Pengaruh Disonansi Emosi Terhadap Turnover Intention: Peran Mediasi Kepuasan Kerja

\title{
PENGARUH DISONANSI EMOSI TERHADAP TURNOVER INTENTION: PERAN MEDIASI KEPUASAN KERJA DAN MODERASI DUKUNGAN SUPERVISOR
}

\author{
Haniul Karomah ${ }^{1 *}$, Ratno Purnomo', Ade Irma Anggraeni ${ }^{1}$ \\ ${ }^{1}$ Program Pascasarjana Magister Manajemen, Universitas Jendral Soedirman Purwokerto, Indonesia \\ *email corresponding author: haniulk030@gmail.com
}

\begin{abstract}
Abstrak
Penelitian ini bertujuan untuk menguji ulang penelitian mengenai pengaruh diosnansi emosi terhadap turnover intention dengan melibatkan kepuasan kerja sebagai mediasi dan dukungan supervisor sebagai moderasi dalam penelitian. Penelitian ini melibatkan 116 perawat sebagai responden di salah satu rumah sakit di gombong. Penelitian ini dilakukan dengan memberikan kuesioner kepada responden. Hasilnya disonansi emosi berpengaruh positif terhadap kepuasan kerja dan berpengaruh negative terhadap turnover intention. Selain itu, kepuasan kerja juga berpengaruh negatif terhadap turnover intention. Penelitian ini juga membuktikan bahwa kepuasan kerja dapat digunakan sebagai mediasi dan dukungan supervisor sebagai moderasi dalam penelitian ini. Kesimpulannya adalah karyawan perlu dilatih untuk melakukan akting mendalam sata bekerja agar tetap puas terhadap pekerjaannya dan memenuhi permintaan pasien.
\end{abstract}

Kata Kunci: Disonansi Emosi, Kepuasan Kerja, Turnover Intention, Dukungan Supervisor

\begin{abstract}
This study aims to re-examine the research on the effect of emotional dissonance on turnover intention by involving job satisfaction as mediation and supervisor support as moderation in research. This study involved 116 nurses as respondents in one of the hospitals in gombong. This research was conducted by giving a questionnaire to respondents. The results show that emotional dissonance has a positive effect on job satisfaction and has a negative effect on turnover intention. In addition, job satisfaction also has a negative effect on turnover intention. This study also proves that job satisfaction can be used as a mediating variable and supervisor support as a moderating variable in this study. The conclusion from this study is that employees need to be trained to do in-depth acting while working to remain satisfied with their work and meet patient demands.
\end{abstract}

Keywords: Emotional Dissonance, Job Satisfaction, Turnover Intention, Supervisor Support.

\section{PENDAHULUAN}

Turnover intention menjadi perhatian dalam banyak organisasi dan menjadi masalah serius yang dihadapi organisasi dimana karyawan meninggalkan organisasi atau organisasi memecat karyawannya (Othman et al., 2018). Wagner (2010) menunjukkan bahwa turnover adalah hasil yang berbahaya karena berhubungan dengan hilangnya individu dan kinerja organisasi, pengurangan signifikan dalam kualitas perawatan, peningkatan beban kerja dari anggota staf yang bertahan dalam turnover, dan kehilangan semangat dan turnover lebih lanjut. Turnover karyawan menjadi salah satu tantangan yang paling signifikan bagi manajer khususnya dalam konteks layanan jasa. (Xu, Martinez, dan Lv, 2017). Prediktor yang paling konsisten dalam penelitian turnover seperti kepuasan kerja, komitmen organisasi, dan turnover intention (Shankar dan Bhatnagar, 2010).

Mempertahankan kesejahteraan karyawan dan membatasi turnover intention penting bagi organisasi. Disonansi emosi menjadi salah satu faktor penting yang berhubungan dengan perilaku 
turnover intention karena masih terdapat inkonsistensi dalam hubungan antara disonansi emosi dengan turnover intention. Hasil penelitian sebelumnya mengenai disonansi emosi dengan turnover intention menunjukkan hubungan yang positif, tetapi masih terdapat hubungan yang tidak signifikan. Penelitian yang dilakukan oleh Zito (2018) menunjukkan bahwa disonansi emosi berhubungan positif dengan turnover intention. Sedangkan penelitian oleh Jung dan Yoon (2014) menunjukkan hasil yang berbeda karena disonansi emosi tidak berhubungan signifikan dengan turnover intention. Oleh karena itu, dalam penelitian ini akan menguji kembali bagaimana hubungan antara disonansi emosi dengan turnover intention menggunakan variabel mediasi.

Penelitian ini dapat menjadi penelitian yang lebih lengkap dengan menambahkan variabel mediasi. Berdasarkan beberapa variabel mediasi yang pernah digunakan untuk menguji disonansi emosi, penelitian ini bermaksud menguji kembali variabel kepuasan kerja sebagai mediasi antara disonansi emosi dengan turnover intention. Hal ini disebabkan kepuasan kerja diketahui memediasi hubungan antara disonansi emosi dengan turnover intention (Abraham, 1999). Sedangkan, menurut temuan Zito et al. (2019) kepuasan kerja tidak signifikan memediasi disonansi emosi dengan turnover intention meskipun disonansi emosi mempunyai hubungan negatif signifikan dengan kepuasan kerja dan positif signifikan dengan turnover intention.

Pengaruh disonansi emosi terhadap turnover intention tidak hanya dipengaruhi oleh variabel mediasi tetapi juga oleh variabel moderasi. Sebagian besar artikel mengenai disonansi emosi berfokus pada hubungan langsung dan baru sedikit yang menguji moderasi untuk disonansi emosi dengan hasil pekerjaan. Oleh karena itu, perlu mengeksplorasi dalam kondisi apa disonansi emosi dapat menurunkan atau meningkatkan turnover intention. Salah satu moderator yang menjadi perhatian adalah dukungan sosial yang diperoleh dari supervisor. Dukungan supervisor diketahui dapat mempengaruhi kepuasan kerja karyawan dan turnover intention. Dukungan supervisor mengurangi pengaruh disonansi emosi terhadap turnover intention. Penelitian ini bertujuan untuk memahami dengan lebih baik pengaruh disonansi emosi terhadap turnover intention dengan mengeksplorasi peran mediasi kepuasan kerja dan peran moderasi dukungan supervisor. Selain itu, penelitian ini juga untuk memberikan jawaban terhadap inkonsistensi dalam hasil penelitian sebelumnya dengan menambahkan variabel mediasi kepuasan kerja dan moderasi dukungan supervisor dalam penelitian ini.

\section{TINJAUAN PUSTAKA DAN HIPOTESIS}

\section{Disonasi Emosi dan Kepuasan Kerja}

Abraham (1999) menunjukkan dalam penelitiannya bahwa teori perbedaan dapat menjelaskan bagaimana disonansi emosi mempengaruhi kepuasan kerja. Menurut teori perbedaan, karyawan mempunyai batas untuk membandingkan kualitas hasil yang diharapkan dan hasil aktual dari pekerjaannya. Hasil aktual dari pekerjaanya menuntut karyawan untuk menampilkan emosi yang bertentangan dan tidak terprediksi yang memicu terjadinya disonansi emosi. Hasil aktual ini berbeda jauh dengan hasil yang diharapkan karyawan sehingga memicu penurunan kepuasan kerja karyawan. Saat mengalami disonansi emosi, karyawan akan menutupi emosinya, bertindak, bersikap atau merespon dengan cara yang berbeda dengan apa yang dirasakan atau dipercaya. 
Penelitian yang dilakukan oleh Talebpour dan Mikaeli (2013) menunjukkan bahwa terdapat korelasi negatif antara kepuasan kerja dan disonansi emosi diantara perawat. Kepuasan kerja akan berkurang dengan adanya disonansi emosi. Ketika disonansi emosi lebih tinggi dibandingkan ratarata, banyak perawat merasakan bahwa mereka mengalami kelelahan dan kesulitan di akhir hari kerja. Penelitian ini didukung oleh Zito et al., (2018) yang menunjukkan bahwa kepuasan kerja berhubungan negatif dengan disonansi emosi. Konflik emosi yang dirasakan dan emosi yang ditampilkan dalam disonansi emosi dapat menurunkan kepuasan kerja karyawan. Menunjukkan emosi yang tidak dirasakan mempunyai peran dalam persepsi terhadap kepuasan kerja yang menurun karena adanya disonansi emosi.

Hipotesis 1 : Disonansi emosi berhubungan negatif dengan kepuasan kerja.

\section{Kepuasan Kerja dan Turnover Intention}

Kepuasan kerja menjadi salah satu antesenden penting dalam penelitian mengenai turnover intention. Banyak penelitian sebelumnya yang menunjukkan saat karyawan mengalami kepuasan rendah, kemungkinan keinginan untuk meninggalkan organisasi lebih besar. Penelitian oleh Saeed et al., (2014) menemukan bahwa kepuasan kerja berhubungan negatif dengan turnover intention. Saat kepuasan kerja tinggi, maka turnover intention akan turun begitu juga sebaliknya. Kepuasan kerja muncul saat terdapat perbedaan antara keuntungan yang diharapkan dan keuntungan yang diterima. Tingginya perbedaan antara keuntungan yang diharapkan dan keuntungan sebenarnya yang diterima menghasilkan turnover intention yang tinggi. Penelitian lain yang dilakukan oleh Shah dan Jumani (2015) menunjukkan terdapat hubungan kuat signifikan antara kepuasan kerja dan turnover intention karena kurangnya kepuasan kerja mendorong orang keluar kerja.

Hipotesis 2: Kepuasan kerja berhubungan negatif dengan turnover intention.

\section{Disonansi Emosi dan Turnover Intention}

Penelitian oleh Zito et al., (2018) menunjukkan bahwa turnover intention berhubungan positif dengan disonansi emosi. Disonansi emosi dapat menurunkan energi karyawan, engagement, dan kesediaan melanjutkan pekerjaan. Penelitian oleh Celik dan Oz. (2011) juga menunjukkan bahwa terdapat hubungan positif antara disonansi emosi dengan turnover intention. Disonansi emosi tinggi menyebabkan turnover intention juga tinggi. Pengaruh disonansi emosi ke turnover intention berhubungan dengan penurunan sumber daya psikologis karyawan. Individu yang mengalami disonansi emosi akan memisahkan diri dari diri mereka sendiri dan organisasinya. Hal ini mengarahkan mereka untuk mencari pekerjaan baru. Berdasarkan hasil penelitian sebelumnya menunjukkan bahwa disonansi emosi akan berhubungan positif dengan turnover intention. saat karyawan mengalami disonansi emosi yang tinggi, maka turnover intention karyawan juga semakin tinggi.

Hipotesis 3 :Disonansi emosi berhubungan positif dengan turnover intention.

\section{Kepuasan Kerja Memediasi Hubungan antara Disonansi Emosi dengan Turnover Intention}

Penelitian yang dilakukan oleh Zito et al., (2019) menggunakan kepuasan kerja sebagai mediasi hubungan antara disonansi emosi dengan turnover intention. Meskipun hasilnya menunjukkan bahwa kepuasan kerja tidak signifikan memediasi disonansi emosi dengan turnover intention tetapi 
disonansi emosi mempunyai hubungan negatif signifikan dengan kepuasan kerja dan positif signifikan dengan turnover intention. Pugh dan Growth (2011) dalam penelitiannya menjelaskan bahwa terjadinya disonansi emosi akan mengarah pada kepuasan kerja menurun. Lewig dan Growth (2003) menyatakan bahwa perbedaan emosi yang dirasakan dan ditampilkan berkontribusi terhadap penurunan kepuasan kerja karyawan. Penurunan kepuasan kerja ini akan mengarahkan karyawan pada turnover intention. Hal ini disebabkan karyawan ingin mencari pekerjaan yang lebih baik. Disonansi emosi akan menstimulasi turnover karyawan melalui ketidakpuasan yang dirasakan karyawan.

Hipotesis 4: Kepuasan kerja akan memediasi hubungan anara disonansi emosi dengan turnover intention

\section{Dukungan Supervisor Memoderasi Hubungan Antara Disonansi Emosi dengan Kepuasan Kerja}

Dukungan supervisor telah menjadi variabel yang digunakan sebagai moderasi dalam beberapa penelitian. Penelitian oleh Achour et al., (2017) menggunakan dukungan supervisor sebagai moderasi hubungan antara work-family demand dan kesejahteraan perempuan. Dukungan supervisor juga memoderasi hubungan antara emotional labor dengan kinerja pekerjaan (HyunJeong, Won-Moo, Tae-Won, dan Jea Kyoon, 2017). Penelitian yang dilakukan oleh Galletta, et.al, (2011) menunjukkan bahwa perawat lebih puas dengan kecukupan perawatan saat dukungan supervisor tinggi. Hal ini membuktikan bahwa dukungan supervisor memoderasi hubungan terhadap kepuasan kerja. Dukungan supervisor memperkuat efek positif deep acting dan mengurangi efek negatif surface acting.

Hipotesis 5: Dukungan supervisor memoderasi hubungan disonansi emosi dengan kepuasan kerja.

\section{Dukungan Supervisor Memoderasi Hubungan antara Kepuasan Kerja dengan Turnover Intention}

Supervisor akan bertindak sebagai bagian dari organisasi yang akan berhubungan langsung dengan karyawan. Penelitian yang dilakukan oleh Tuzun dan Kalemci (2012) menunjukkan bahwa dukungan supervisor memoderasi hubungan antara dukungan organisasi yang dirasakan dengan turnover intention. Supervisor akan menilai kontribusi karyawan terhadap organisasi. Dukungan supervisor yang dirasakan oleh karyawan akan berpengaruh terhadap keputusan karyawan terkait dengan turnover intention (Galetta et al., 2011). Saat karyawan merasakan kebebasan, independen, jadwal kerja fleksibel dan dapat membuat keputusan sendiri, maka tingkat turnover intention akan lemah saat karyawan merasakan dukungan supervisor yang tinggi. Hal ini menujukkan bahwa dukungan supervisor akan mengurangi dampak merugikan yang disebabkan oleh pekerjaan.

Hipotesis 6 : Dukungan supervisor memoderasi hubungan kepuasan kerja dengan turnover intention.

\section{METODE PENELITIAN}

Penelitian ini termasuk jenis penelitian ex post facto atan tanpa perlakuan. Pengambilan data dalam penelitian ini menggunakan metode cross-sectional dengan sekali pengambilan. Penelitian dilakukan di salah satu rumah sakit swasta di Gombong dengan menyebarkan kuesioner kepada perawat 
sebagai responden. Responden dalam peneltian ini berjumlah 116 perawat yang dipilih menggunakan metode purposive sampling.. Kuesioner yang digunakan dalam penelitian ini diadaptasi dari penelitian sebelumnya dan diterjemahkan ke dalam Bahasa Indonesia. Analisis data untuk pengujian hipotesis menggunakan uji regresi dengan bantuan software SPSS.

\section{HASIL DAN PEMBAHASAN}

Data penelitian yang diperoleh dari kuesioner dilakukan pengolahan dan analisis untuk menguji hipotesis penelitian. Hasil analisis data pada penelitian ini adalah sebagai berikut:

Tabel 1. Mean, Standar Deviasi, Korelasi

\begin{tabular}{lllllll}
\hline & Mean & SD & ED & JobSat & TI & SS \\
\hline ED & 41.034 & 3.513 & 1 & & & \\
JobSat & 39.612 & 3.928 & $0.359^{\prime \prime}$ & 1 & & \\
TI & 16.025 & 4.118 & $-0.372^{\prime \prime}$ & $-0.382^{\prime \prime}$ & 1 & \\
SS & 34.051 & 2.698 & $0.367^{\prime \prime}$ & $0.432^{\prime \prime}$ & $-0.207^{\prime}$ & 1 \\
\hline
\end{tabular}

Sumber: Data Primer Diolah, 2020

Perawat memiliki tingkat disonansi emosi, kepuasan kerja, dan dukungan supervisor yang tinggi, serta tingkat turnover intention yang rendah. Disonansi emosi dengan kepuasan kerja memiliki korelasi positif artinya semakin tinggi disonansi emosi, maka kepuasan kerja juga tinggi. Korelasi antara kepuasan kerja dengan turnover intention negatif. Hal ini disebabkan saat kepuasan kerja tinggi, maka turnover intention karyawan akan rendah. Disonansi emosi juga memiliki korelasi negatif dengan turnover intention. Hal ini dapat disebabkan karena disonansi emosi tidak selalu menjadi penyebab terjadinya turnover. Selain itu, dukungan supervisor memiliki korelasi positif dengan disonansi emosi dan kepuasan kerja serta korelasi negatif dengan turnover intention. Hal ini dapat disebabkan dengan tingginya dukungan supervisor yang diterima akan meningkatkan kepuasan kerja karyawan dan menurunkan turnover intention karyawan.

Tabel 2. Analisis Regresi Linear

\begin{tabular}{lllll}
\hline Regresi & $\mathrm{B}$ & $\mathrm{t}$ & $\mathrm{Sig}$ & Hasil \\
\hline Disonansi Emosi -Kepuasan Kerja & 0.401 & 4.103 & 0.000 & Ditolak \\
Kepuasan Kerja-Turnover Intention & -0.401 & -4.420 & 0.000 & Diterima \\
Disonansi Emosi -Turnover Intention & -0.436 & -4.279 & 0.000 & Diterima \\
\hline
\end{tabular}

Analisis data yang ditelah dilakukan menunjukkan bahwa hipotesis 1 ditolak karena disonansi emosi berpengaruh positif terhadap kepuasan kerja. Hal ini dapat disebabkan ketika perawat merasakan lebih banyak disonansi emosi yang merupakan hasil dari akting permukaan (surface acting), mereka merasakan sedikit kelelahan emosional dan lebih puas dengan profesinya. 
Penemuan ini memang bertolak belakang dnegan hipotesis penelitan dan penelitian sebelumnya, tetapi dapat mendukung penelitian lain, seperti yang dilakukan oleh Hoschild (1983) dalam Chu dan Morris (2012). Karyawan yang baru direkrut biasanya akan menunjukkan akting yang tulus, tetapi seiring berjalannya waktu mereka akan seidikit demi sedikit menggunakan akting permukaan sebagai perlindungan diri dari pengalaman yang tidak menyenangkan dengan klien. Karyawan sangat peduli bagaimana mereka dilihat orang lain karena akan berpengaruh terhadap aktivitas promosi, tingkat kompeten, dan penghargaan yang sehingga karyawan sering memalsukan emosinya agar dapat diterima di lingkungan kerja.

Penemuan lain menunjukkan bahwa kepuasan kerja berpengaruh negatif dengan turnover intention. Hal ini telah sesuai dengan hipotesis penelitian dan juga penelitian sebelumnya. Hal ini disebabkan saat perawat puas terhadap pekerjaannya, kecil kemungkinan untuk berpindah ke tempat kerj lain kecuali ada faktor lain di luar kepuasan kerja. Saat harapan mereka sesuai dengan apa yang mereka dapatkan, maka mereka akan merasakan emosi positif yang akan menginduksi mereka memandang bahwa pekerjaan mereka menarik, menantang, memuaskan, dan dapat menjadi tempat berkembang diri (Mahdi, at al., 2012). Saat kepuasan kerja tinggi, maka tingkat turnover intetion juga akan menurun karena semua kebutuhan mereka telah terpenuhi.

Hasil untuk hipotesis ketiga menunjukkan hasil yang berbeda dengan apa yang telah dihipotesiskan. Hasilnya menunjukkan bahwa disonansi emosi ini berpengaruh negatif terhadap turnover intention. Meskipun penelitian sebelumnya mengenai variabel ini telah menunjukkan hasil yang positif, tetapi dalam penelitian ini ada faktor lain yang menyebabkan turnover intention perawat (Ferdik, Smith, dan Applegate, 2014). Selain itu, sudah dijelaskan sebelumnya bahwa perawat menerima pelatihan selama masa pendidikan bagaimana mengendalikan emotional labor sehingga saat mengalami disonansi emosi yang tinggi tetap dapat bekerja dengan baik dan nyaman. Perawat juga lebih banyak menggunakan acting permukaan maupun akting mendalam dalam bekerja sehingga tidak akan terlalu banyak mengalami kelelahan emosi saat bekerja yang akhirnya mengarah pada turnover intention.

Tabel 3. Analisis Mediasi

\begin{tabular}{ccccc}
\hline Langkah regresi & B & SE & T & Sig \\
\hline $\begin{array}{c}\text { Langkah 1 } \\
\text { Disonansi Emosi -Turnover Intention } \\
\quad \text { Langkah 2 }\end{array}$ & -0.436 & 0.102 & -4.279 & 0.000 \\
$\begin{array}{c}\text { Disonansi Emosi -Kepuasan Kerja } \\
\text { Langkah 3 }\end{array}$ & 0.401 & 0.098 & 4.103 & 0.000 \\
\hline
\end{tabular}


Disonansi Emosi, Kepuasan Kerja- Turnover Intention

Analisis yang telah dilakukan menunjukkan bahwa kepuasan kerja dapat memediasi hubungan antara disonansi emosi dengan dengan turnover intention. Hal ini dapat diartikan bahwa tinggi maupun rendahnya tingkat disonansi emosi seseorang akan mempengaruhi turnover intention melalui pengaruh kepuasan kerja yang dirasakan seseorang. Seseorang memiliki disonansi emosi yang tinggi tetapi tingkat turnover intention tetap akan rendah apabila memiliki kepuasan kerja yang tinggi. Hal ini menunjukkan bahwa kepuasan kerja dapat memediasi hubungan antara disonansi emosi dengan turnover intention.

Tabel 4. Analisis Moderasi

\begin{tabular}{|c|c|c|c|}
\hline Regresi & B & $\mathrm{T}$ & Sig \\
\hline \multicolumn{4}{|l|}{ Persamaan 1} \\
\hline \multicolumn{4}{|l|}{ Langkah 1} \\
\hline Disonansi Emosi -Kepuasan Kerja & 0.401 & 4.103 & 0.000 \\
\hline \multicolumn{4}{|l|}{ Langkah 2} \\
\hline Disonansi Emosi, Dukungan Supervisor-Kepuasan Kerja & 0.505 & 3.914 & 0.000 \\
\hline \multicolumn{4}{|l|}{ Langkah 3} \\
\hline Disonansi Emosi, Interaksi, Dukungan Supervisor- & 0.066 & 2.060 & 0.042 \\
\hline \multicolumn{4}{|l|}{ Kepuasan Kerja } \\
\hline \multicolumn{4}{|l|}{ Persamaan 2} \\
\hline \multicolumn{4}{|l|}{ Langkah 1} \\
\hline Kepuasan Kerja -Turnover Intention & -0.401 & -4.420 & 0.000 \\
\hline \multicolumn{4}{|l|}{ Langkah 2} \\
\hline Kepuasan Kerja , Dukungan Supervisor-Turnover Intention & -0.078 & -0.531 & 0.597 \\
\hline \multicolumn{4}{|l|}{ Langkah 3} \\
\hline Kepuasan Kerja, Interaksi, Dukungan Supervisor- Turnover & 0.073 & 2.258 & 0.026 \\
\hline Intention & & & \\
\hline
\end{tabular}

Hasil analisis dan pembahasan sebelumnya menunjukkan bahwa disonansi emosi berpengaruh positif terhadap kepuasan kerja dimana hasilnya berbeda dengan hipotesis penelitian. Hal ini dapat disebabkan salah satunya oleh adanya dukungan moderasi yang tinggi yang dirasakan oleh perawat saat bekerja. Dukungan supervisor dalam penelitian ini berperan sebagai moderator dalam hubungan antara disonansi emosi dengan kepuasan kerja. Meskipun perawat mengalami disonansi emosi yang tinggi, tetapi diharapkan dengan adanya dukungan supervisor yang tinggi kepuasan kerja perawat tetap akan tinggi. Penemuan sesuai dengan penelitian sebelumnya yang dilakukan oleh Galetta et al., (2011) yang menunjukkan bahwa perawat akan lebih puas terhadap 
pekerjaannya saat dukungan supervisor yang diterima lebih tinggi. Dukungan supervisor yang tinggi akan memperkuat efek positif dari akting mendalam dan memperlemah efek negatif akting permukaan sehingga meskipun mengalami pengalaman yang tidak menyenangkan dalam bekerja tetap dapat mempertahankan kepuasan kerjanya (Chen et al., 2012).

Penelitian ini juga mendukung penemuan yang menunjukkan bahwa dukungan supervisor juga memoderasi hubungan kepuasan kerja dengan turnover intention. Supervisor akan berperan sebagai agen dari organisasi yang akan berhubungan langsung dengan karyawan dalam hal ini perawat. Supervisor di sini akan menilai kontribusi perawat, memberikan dukungan, memberikan penghargaan yang akhirnya membuat kepuasan perawat tinggi sehingga tingkat turnover intention rendah. Meskipun perawat harus tetap keluar tetapi tetap dapat diminimalkan dan diharapkan penyebabnya bukan karena rendahnya kepuasan kerja tetapi faktor lain. Hal ini yang terjadi di dalam tempat penelitian yang telah dilakukan. Meskipun kepuasan kerja sudah tinggi dan turnover intention rendah, tetapi tetap ada yang keluar.

\section{KESIMPULAN}

Berdasarkan hasil penelitian disimpulkan bahwa disonansi berpengaruh positif terhadap kepuasan kerja dan berpengaruh negatif terhadap turnover intention, sedangkan kepuasan kerja berpengaruh negatif terhadap turnover intention. Kepuasan kerja berperan sebagai mediasi dan dukungan supervisor sebagai moderasi dalam penelitian ini. Hasil penelitian dapat menjadi bahan pertimbangan bagi kepala ruangan (supervisor) untuk menekankan penggunaan akting mendalam dalam berinteraksi dengan pasien. Selain itu, Diharapkan tingginya dukungan supervisor akan tetap dipertahankan dan bahkan ditingkatkan lagi sehingga efek negatif disonansi emosi juga akan semakin rendah. Pengambilan data dalam penelitian ini memiliki keterbatasan karena bersamaan dengan pandemic Covid-19. Oleh karena itu, penelitian selanjutnya dapat menguji ulang penelitian ini di dalam tempat setting layanan jasa yang sama atau berbeda.

\section{DAFTAR PUSTAKA}

Abraham, R. (1999). The impact of emotional dissonance on organizational commitment and intention to turnover. The Journal of Psychology. 133. 441-455.

Achour, M., Khalil, S.A., Ahmad, B., Nor, M.R., Yusoff, M.Y.Z. (2017). Management and supervisory support as a moderator of work-family demands and women's well-being: A case study of Muslim female academicians in Malaysia. Humanomics. 33..335-356. 
Brotheridge, C.M. dan Grandey, A. (2002). Emotional labor and burnout: comparing two perspectives of people work. Journal of Vocational Behavior. 60. 17-39.

Celik, D.A., dan Oz, E.U. (2011). The effects of emotional dissonance and quality of work life perceptions on absenteeism and turnover intentions among Turkish call center employees. Procedia - Social and Behavioral Sciences. 30. 2515 - 2519.

Chen, Z., Sun, H., Lam, W., Hu, Q., Huo, Y., dan Zhong, J.A. (2012). Chinese hotel employees in the smiling masks: roles of job satisfaction, burnout, and supervisory support in relationships between emotional labor and performance. The International Journal of Human Resource Management. 23. 4. 826-845.

Cheung, F.Y., dan Tang, C.S. (2012). The effect of emotional dissonance and emotional intelligence on work-family interference. Canadian Journal of Behavioural Science. 44. 1. 50-58.

Choi, S., Cheong, K., dan Feinberg, R.A. (2012). Moderating effects of supervisor support, monetary rewards, and career paths on the relationship between job burnout and turnover intentions in the context of call centers. Managing Service Quality. 22. 5. 492-516.

Chu, K.H., Baker, M.A., dan Murrmann, S.K. (2012). When we are on stage, we smile: The effects of emotional labor on employee work hasils. International Journal of Hospitality Managemen. 31. 906-915.

Cortese C.G dan Quaglino, G.P. (2006). The measurement of job satisfaction in organizations: a comparison between a facet scale and a single-item measure. TPM Test Psychom Methodol Appl Psychol. 13. 4. 305-316.

Cortese, C.G. (2013). Predictors of intention to leave the nursing profession in two Italian hospitals. Assist Inferm Ric. 32. 20-27.

Côté, S. (2005). A social interaction model of the effects of emotion regulation on work strain. The Academy of Management Review. 30. 509-530.

Das, D., Nandialathb, A., dan Mohanc, R. (2013). Feeling unsure: quit or stay? Uncovering heterogeneity in employees' intention to leave in Indian call centers. Int J Hum Resour Man. 24. 1. 15-34.

Dollard, M.F., et.al. (2003). Unique aspects of stress in human service work. Australian Psychologist. 38. 84-91.

Dysvik, A., dan Kuvaas, B. (2013). Perceived job autonomy and turnover intention: The moderating role of perceived supervisor support. European Journal of Work and Organizational Psychology. 22. 5.

Eisenberger R., Huntington R., Hutchison S. dan Sowa D. (1986). Perceived organizational support. Journal of Applied Psychology. 71. 500-507.

Ferdik, F.V., Smith, H.P., dan Applegate, B. (2014): The role of

emotional dissonance and job desirability in predicting correctional officer turnover intentions. Criminal Justice Studies: A Critical Journal of Crime, Law and Society. pp.1-21. 
Galletta, M., et.al. (2011). Turnover intention among Italian nurses: The moderating roles of supervisor support and organizational support. Nursing and Health Sciences. 13.184-191.

Glissmeyer, M., Bishop J. W., dan Fass, R. D. (2008). Role conflict, role ambiguity and intention to quit the organization: The case of law enforcement. Academy of Management Journal. 40. 1. 82111.

Grandey, A.A., Tam, A.P., dan Brauburger, A.L. (2002). Affective states and traits in the workplace: Diary and survey data from young workers. Motivation and Emotion. 26. 1.

Grandey, A. A., Diefendorff, J. M., dan Rupp, D. E. (2013). Emotional labor in the 21st Century. Diverse perspectives on emotion regulation at work. New York: Routledge.

Greenhaus, J. H., Parasuraman, A., dan Wormley, W. M. 1990. Effects of race on organizational experiences, job performance evaluations, and career hasils. Academy of Management Journal. 31. 1. 64-84.

Heuven, E., Bakker, A.B., Schaufeli, W.B., dan Huisman, N. (2006). The role of self-efficacy in performing emotion work. Journal of Vocational Behavior. 69. 222-235.

Higgins, E.T., Klein, R., dan Strauman, T. (1985). Self-concept discrepancy theory: a psychological model for distinguishing among different aspects of depression and anxiety. Social Cognition. 3. 1. 51-76.

Higgins, E.T. (1987). Self-discrepancy: A theory relating self and affect. Psychological Review. 94. 3. 319-340

Hofaidhllaoui, M., dan Chhinzer, N. (2014). The relationship between satisfaction and turnover intentions for knowledge workers. Engineering Management Journal. 26. 3-9.

Holman, D., Martinez-iñigo, D., dan Totterdell, P. (2008). Emotional labour and employee well-being: An integrative review. Research companion to emotion in organizations. 301-315.

Holtom, B.C., Mitchell, T.R., Lee, T.W., dan Eberly, M.B. (2008). 5 turnover and retention research: A glance at the past, a closer review of the present, and a venture into the future. The Academy of Management Annals. 2.1.231-274.

Hülsheger, U. R., dan Schewe, A. F. (2011). On the costs and benefits of emotional labor: A metaanalysis of three decades of research. Journal of Occupational Health Psychology. 16. 361389.

Iplik, F.N., Topsakal, Y., dan Iplik, E. (2014). The effects of emotional labor on job attitudes of hotel employees: Mediating and moderating roles of social support and job autonomy. International Review of Management and Marketing. 4. 3. 175-186.

Jin, M., McDonald, B., dan Park, J. (2016). Followership and job satisfaction in the public sector: The moderating role of perceived supervisor support and performance-oriented culture. International Journal of Public Sector Management. 29. 3. 218-237.

Johanson, M. M., dan Woods, R. H. (2008). Recognizing the emotional element in service excellence. Cornell Hospitality Quarterly. 49. 3. 310-316. 
Jung, H.S., dan Yoon, H.H. (2014). Antecedents and consequences of employees' job stress in a foodservice industry: Focused on emotional labor and turnover intent. International Journal of Hospitality Management. 38. 84-88.

Kang, H., Gatling, A., dan Kim, J. (2015) The impact of supervisory support on organizational commitment, career satisfaction, and turnover intention for hospitality frontline employees. Journal of Human Resources in Hospitality dan Tourism. 14. 1. 68-89.

Kang, S., dan Kang, S. (2016). High-commitment human resource management and job stress: supervisor support as a moderator. Social Behavior And Personality. 44. 10. 1719-1732.

Karatepe, O.M. (2011). Do job resources moderate the effect of emotional dissonance on burnout?. International Journal of Contemporary Hospitality Management. 23. 44- 65.

Karatepe, O. M., dan Vatankhah, S. (2014). The effects of high-performance work practices on perceived organizational support and turnover intentions: Evidence from the airline industry. Journal of Human Resources in Hospitality dan Tourism. 13. 2. 103-119.

Karimi, et al. (2016). Are organisational factors affecting the emotional withdrawal of community nurses?. Australian Health Review. 41. 4. 359-364.

Kim, K., dan Jogaratnam. (2010). Effects of individual and organizational factors on job satisfaction and intent to stay in the hotel and restaurant industry. Journal of Human Resources in Hospitality dan Tourism. 9. 3. 318-339.

Kim, H.J., Hur, W., Moon, T., dan Jun, J. (2017). Is all support equal? The moderating effects of supervisor, coworker, and organizational support on the link between emotional labor and job performance. BRQ Bus. Res. Q. 20.124-136.

Kinman, G., Wray, S., dan Strange, C. (2011). Emotional labour, burnout and job satisfaction in UK teachers: the role of workplace social support. Educational Psychology: An International Journal of Experimental Educational Psychology. 31. 7. 843-856.

Lewig, K.A., dan Dollard, M.F. (2003). Emotionaal dissonance, emotional exhaustion and job satisfaction in call centres. European Journal of Work and Organizational Psychology. 12. 4. 366-392.

Macdonald. S., dan MacIntyre, P. (1997). The generic job satisfaction scale: Scale development and its correlates. Employee Assistance Quarterly. 13. 2. 1-16.

Mahdi, A.S., Zin, M.Z., Nor, M.R., Sakat, A.A., dan Naim, A.S. (2012). the relationship between job satisfaction and turnover intention. American Journal of Applied Sciences. 9 9. 1518-1526.

Mbah, S.E., dan Ikimefuna, C.O. (2012). Job satisfaction and employees' turnover intentions in total Nigeria plc. in Lagos State. International Journal of Humanities and Social Science. 2. 275-287.

Mobley, W.H., Horner, S.O., dan Hollingsworth, A.T. (1978). An evaluation of precursors of hospital employee turnover. Journal of Applied Psychology. 63. 4. 408-414.

Morris, J.A., dan Feldman, D.A. (1996). The dimensions, antecedents, and othconsequences of Emotional Labor. Academy of Management Review. 21. 986-1010. 
Othman, et al. (2018). The mediating role of emotional exhaustion on the relationship between job factors and turnover intention among service employees. Proceedings of the $2 n d$ Advances in Business Research International Conference. 221-231.

Park, J. S dan Kim, T. H. (2009). Do types of organizational culture matter in nurse job satisfaction and turnover intention?. Leadership in Health Services. 22. 1. 20-38.

Pugh, S.D., Groth, M., dan Hennig, T. (2011). Willing and able to fake emotions: a closer examination of the link between emotional dissonance and employee well-being. Journal of Applied Psychology. 96. 2. 377-390.

Rafaeli, A., dan Sutton, R. (1987). Expression of emotion as part of the work role. Acudemy of Management Review. 12.23-37.

Saeed, I., Waseem, M., Sikander, S., dan Rizwan, M. (2014). The relationship of turnover intention with job satisfaction, job performance, leader member exchange, emotional intelligence. International Journal of Learning dan Development. 4. 2. 242-256.

Shah, N. H., dan Jumani, N.B. (2015). Relationship of job satisfaction and turnover intention of private secondary school teachers. Mediterranean Journal of Social Sciences. 6. 4.

Shankar, T. 2010. Work life balance, employee engagement, emotional consonance/dissonance dan turnover intention. Indian Journal of Industrial Relations. 46. 1. 74-78.

Talebpour, A., Mikaeli, J., dan Khoshdel, M.K. (2013). Investigating Effective Factors on emotional dissonance among nurses: Case Study Tehran West Region Hospital's. Mediterranean Journal of Social Sciences. 4. 6. 174-181.

Tuzun, I.K., dan Kalemci, R.A. (2012). Organizational and supervisory support in relation to employee turnover intentions. Journal of Managerial Psychology. 27. 5.

van Dam, K., Meewis, M., dan van der Heijden, B.I. (2013). Securing intensive care: towards a better understanding of intensive care nurses' perceived work pressure and turnover intention. $J$ Adv Nurs. 69. 1. 31-40.

Venilla, M dan Vivekanandan, K. (2016). A study on how emotional dissonance impact work exhaustion, job satisfaction and turnover intention among IT' professionals. International Journal of Management. 8. 01-12.

Wagner, C.M. (2010). Predicting nursing turnover with catastrophe theory. J. Adv. Nurs. 66. 20712084.

Wegge,J., Dick, R.F., dan Bernstorff, C.( 2010). Emotional dissonance in call centre work. Journal of Managerial Psychology. 25. 6. 596 - 619.

Weiss, H.M., dan Ceopanzano, R. (1996). Structure, causes and consequences of affective experiences at work. Research in Organizational Behavior. 18. 1-74.

Weiss, H.M. (2002). Deconstructing job satisfaction: Separating evaluations, beliefs and affective experiences. Hum Resour Manage R. 12. 2. 173-194. 
Xu, S., Martines, L.R., dan Lv, Q. (2017)._Explaining the link between emotional labor and turnover intentions: The role of in-depth communication. International Journal of Hospitality dan Tourism Administration. 1-19

Zito, M., Emanuel, F., Molino, M., Cortese, C.G., Ghislieri, C., Colombo, L. (2018). Turnover intentions in a call center: The role of emotional dissonnace, job resources, and job satisfaction. PLoS ONE. 13.1-16. 